\title{
Ventilatory function in Nigerian coal miners
}

\author{
B L JAIN ${ }^{1}$ AND J M PATRICK ${ }^{2}$ \\ From the Department of Physiology, ${ }_{1}^{1}$ College of Medicine, University of Lagos, Lagos, Nigeria, and the \\ Department of Physiology and Pharmacology, ${ }^{2}$ University Medical School, Nottingham NG7 2UH, UK
}

\begin{abstract}
Ventilatory capacity has been measured in 675 Nigerian colliery employees classified in three groups according to occupation: coalface workers, other underground workers with low exposure to dust, and surface workers in administrative and clerical jobs. Men with current respiratory symptoms were excluded, as were ex-miners. The faceworkers were a slightly older group who smoked less, and they were presumed to be more active. Faceworkers had the highest forced vital capacities (adjusted for age and stature) but the lowest values for indices reflecting maximal expiratory airflows ( $\mathrm{FEV}_{1} / \mathrm{FVC}$, PFR, FEF, and FMF). Apparently coalface work is associated with an $8 \%$ impairment of maximum expiratory airflow, probably due to dust exposure, but also with a modest enhancement in FVC, possibly due to training of the respiratory muscles. Regression coefficients on age for the airflow indices are significantly more negative in faceworkers than in the other groups. Smoking and duration of service did not significantly affect the pattern of results. FEV $_{1}$ does not vary among the occupational groups in the colliery, and the mean value is close to that predicted on the basis of reference equations previously obtained for non-miners in Nigeria.
\end{abstract}

Much information is available about lung function in coal miners with or without symptomatic or radiological evidence of pneumoconiosis in Europe, ${ }^{1-4}$ in America, ${ }^{5}$ and in South Africa. ${ }^{6}$ Little evidence has been collected in the less industrialised countries of the tropics, where mining practice and dust-control methods may differ substantially, and where the ventilatory capacities of the population are known to be less than those of Europeans. ${ }^{78}$ Bouhuys $^{9}$ has pointed out the lack of detailed attention to environmental health hazards in developing countries, where control of working conditions may be less strict. This study of a substantial sample of men currently employed in a Nigerian colliery attempted to determine the extent to which ventilatory capacity in Africans is impaired by chronic exposure to coal dust. Account was taken of duration of exposure and use of tobacco, but no chest radiographs or details of individual dust exposures were available.

The findings have been presented to the Nigerian Physiological Society.

\section{Materials and methods}

SUBJECTS

The subjects studied were employees of the Coal Mine Corporation of Nigeria in Enugu in Eastern

Received 20 March 1980

Accepted 13 October 1980
Nigeria $\left(7^{\circ} 25^{\prime} \mathrm{E}, 6^{\circ} 20^{\prime} \mathrm{N}\right)$. They were predominantly Ibo, with a small complement from neighbouring tribes. The complete list of some 3000 men was divided into three main groups.

Group 1 (faceworkers) spent all their working hours at the coal face. As the extraction process was only partially mechanised, the energy expenditure of this group may be presumed to be high.

Group 2 (other underground workers) contained men who spent at least part of their time underground; it includes haulage workers, technicians, fitters, and labourers. This group is less exposed to coal dust than the faceworkers.

Group 3 (surface workers) were men in clerical or supervisory jobs, and were not materially exposed to coal dust. Arbitrary quotas of 300,300 , and 100 subjects were set for the three groups, and recruitment from a randomly ordered list of workers was continued until these quotas were achieved. There was no difference in response rates among the groups and no reason to believe that the responders do not broadly represent the whole work force.

\section{PROCEDURES}

The subjects were seen in groups of about 20 on two mornings a week at the Colliery Hospital, Enugu.

Name, age, ethnic group, occupation, duration of service, smoking and snuff-taking habits, height without shoes, and weight in light clothing were 
recorded. A trained technician, under the direct supervision of BLJ, measured vital capacity and then five forced expiratory spirograms using a dry wedgespirometer (Vitalograph Ltd, Buckingham) fitted with an exhalation water filter and modified to allow a ball-point pen to write on a Xeroxed chart. Twenty spirograms recorded with this and with the unmodified instrument showed that no alteration in calibration had been introduced. The subject was then examined clinically for symptoms or signs of current chest disease. Several efforts with a Wright peak flow meter (Airmed, Harlow, UK) were then recorded. No radiographic facilities or medical records were available, and reliable occupational histories were difficult to obtain in the absence of independent contemporary records.

\section{VENTILATORY INDICES MEASURED}

From the spirograms the highest values of the following indices were measured: forced vital capacity (FVC), forced expiratory volume in 1 second $\left(\mathrm{FEV}_{1}\right)$, forced expiratory flow $0 \cdot 2-1 \cdot 2_{1}$ (FEF), forced midexpiratory flow measured over the middle $50 \%$ of the FVC (FMF), and FEV/FVC $\times 100\left(\mathrm{FEV}_{1} \%\right)$. All tests were done with the subject standing, and values were converted to BTPS. Fifty-one records were technical failures, usually because the subject was unable to complete or replicate the spirogram. Only five subjects had any symptoms or signs of current chest disease, and they were excluded.

\section{ANALYSIS}

The data have been analysed using SPSS and GLIM programs for multiple regression and analysis of variance at the Cripps Computer Centre, University of Nottingham. In significance tests a critical p-value of 0.05 has been used.
For each index, multiple regression analysis on age, stature, mass, and mass/stature ${ }^{2}$ was performed. Mass and mass/stature ${ }^{2}$ never contributed more than $3.5 \%$ to $\mathbf{R}^{2}$, the coefficient of multiple determination, and have been excluded from further analysis. Stature contributed significantly to the description of FVC, FEV 1 , and PFR only $(24,17$, and $9 \%$ respectively). Allowance for stature has been made by assuming a linear relation with staturesquared for these three indices, following Cole ${ }^{10}$ who used it for FVC and FEV 1 only.

\section{Results}

ANTHROPOMETRY, DURATION OF SERVICE AND SMOKING HABIT (table 1)

The faceworkers (group 1) were slightly but significantly older than the other groups but did not differ in physique. They had a significantly longer median duration of service, and smoked less. Most of these miners took their tobacco in the form of a locally made snuff: smoking was a habit predominantly of younger men and of those in the less dusty occupations.

\section{VENTILATORY INDICES AT DIFFERENT AGES (table 2)}

The general decline with age in all variables is seen. Age may be allowed for by adjusting all ventilatory indices to a common age of 40 years. The regression coefficients used for this adjustment have been derived from the present data as there is no comprehensive set of reference regression equations applicable to Nigerian subjects. To avoid the influence of any occupational factor on the coefficients for this analysis, a common regression slope on age for each index has been calculated for the

Table 1 Characteristics of 675 Nigerian mining employees studied, tabulated by occupational group

\begin{tabular}{|c|c|c|c|c|c|}
\hline & & $\begin{array}{l}\text { Group 1 } \\
\text { Faceworkers } \\
(n=291)\end{array}$ & $\begin{array}{l}\text { Group } 2 \\
\text { Other } \\
\text { underground } \\
(n=286)\end{array}$ & $\begin{array}{l}\text { Group } 3 \\
\text { Surface } \\
(n=98)\end{array}$ & $\begin{array}{l}\text { Total } \\
(n=675)\end{array}$ \\
\hline Age (yr) & $\begin{array}{l}\text { Mean } \\
\text { SEM } \\
\text { Range }\end{array}$ & $\begin{array}{c}42 \cdot 4 \\
0 \cdot 22 \\
30-52\end{array}$ & $\begin{array}{c}38 \cdot 3 \\
0 \cdot 45 \\
18-56\end{array}$ & $\begin{array}{c}37 \cdot 5 \\
0 \cdot 82 \\
19-52\end{array}$ & $\begin{array}{c}40 \cdot 0 \\
0 \cdot 25 \\
18-56\end{array}$ \\
\hline Stature (m) & $\begin{array}{l}\text { Mean } \\
\text { SEM } \\
\text { Range }\end{array}$ & $\begin{array}{l}1.692 \\
0.004 \\
1.55-1.91\end{array}$ & $\begin{array}{l}1.690 \\
0.004 \\
1.51-1.88\end{array}$ & $\begin{array}{l}1 \cdot 692 \\
0 \cdot 007 \\
1 \cdot 52-1 \cdot 83\end{array}$ & $\begin{array}{l}1.691 \\
0.003 \\
1.51-1.91\end{array}$ \\
\hline Mass (kg) & $\begin{array}{l}\text { Mean } \\
\text { SEM } \\
\text { Range }\end{array}$ & $\begin{array}{c}63 \cdot 7 \\
0 \cdot 39 \\
47-80\end{array}$ & $\begin{array}{c}63 \cdot 3 \\
0 \cdot 47 \\
45-94\end{array}$ & $\begin{array}{c}65 \cdot 4 \\
0 \cdot 89 \\
47-85\end{array}$ & $\begin{array}{c}63 \cdot 7 \\
0 \cdot 29 \\
45-94\end{array}$ \\
\hline Duration of service (yr) & $\begin{array}{l}\text { Median } \\
\text { Max }\end{array}$ & $\begin{array}{l}10 \\
32\end{array}$ & $\begin{array}{r}4 \\
31\end{array}$ & $\begin{array}{r}5 \\
32\end{array}$ & $\begin{array}{r}9 \\
32\end{array}$ \\
\hline Percentage taking snuff & & $83 \cdot 5$ & $65 \cdot 4$ & $55 \cdot 1$ & $71 \cdot 7$ \\
\hline Percentage smoking (No in age-group) & $\begin{array}{l}\text { Total } \\
<35 \mathrm{yr} \\
>35 \mathrm{yr}\end{array}$ & $\begin{array}{l}4 \cdot 5 \\
0 \quad(7) \\
4 \cdot 6(284)\end{array}$ & $\begin{array}{r}10 \cdot 3 \\
27 \cdot 5(69) \\
4 \cdot 7(212)\end{array}$ & $\begin{array}{l}8 \cdot 3 \\
13 \cdot 8(29) \\
6 \cdot 0(67)\end{array}$ & $\begin{array}{r}7 \cdot 5 \\
21 \cdot 9(105) \\
4 \cdot 8(563)\end{array}$ \\
\hline
\end{tabular}


whole of the data, allowing any inter-group differences to affect only the intercept term of the regression equation. The indices had first been adjusted to a common stature where appropriate by multiplying by $(1 \cdot 7 / \text { stature })^{2}$.

Table 3 shows the mean values for the six indices adjusted for age and stature. Faceworkers differed significantly from surface workers: FEV $\%$, PFR, and FEF were lower by $3 \%, 8 \%$, and $16 \%$ respectively, and FMF in faceworkers was $7 \%$ lower than in the other groups combined. The faceworkers, however, had significantly higher FVC than the others, while $\mathrm{FEV}_{1}$ did not differ significantly among the groups. For all the indices, men in group 2 (other underground workers) tended to lie between the other two groups, but did not differ significantly from the men in group 3 (surface workers).

\section{OCCUPATIONAL INFLUENCES ON THE}

DECLINE WITH AGE

Intergroup differences were also expressed in terms of regressions of the ventilatory indices on age. Following Cole, ${ }^{10}$ who showed that ethnic and sex differences are proportional rather than additive, the

Table 2 Mean stature and respiratory variables for 675 Nigerian mining employees studied, tabulated by occupational group and age-group

\begin{tabular}{|c|c|c|c|c|c|c|c|c|c|}
\hline & \multicolumn{8}{|c|}{ Age-group (years) } & \multirow[t]{2}{*}{ Total } \\
\hline & $<20$ & $20-24$ & $25-29$ & $30-34$ & $35-39$ & $40-44$ & $45-49$ & $\geqslant 50$ & \\
\hline & & & & & & & & & $(42 \cdot 4 \mathrm{yr})$ \\
\hline Faceworkers & 0 & 0 & 0 & 7 & 38 & 144 & 95 & 7 & 291 \\
\hline Stature (m) & & & & $1 \cdot 69$ & $1 \cdot 70$ & 1.69 & $1 \cdot 70$ & $1 \cdot 67$ & $1 \cdot 69$ \\
\hline FVC (1) & & & & $3 \cdot 41$ & 3.90 & $3 \cdot 62$ & $3 \cdot 56$ & $3 \cdot 45$ & $3 \cdot 63$ \\
\hline $\mathrm{FEV}_{1}$ (l) & & & & $2 \cdot 60$ & $3 \cdot 15$ & $2 \cdot 90$ & $2 \cdot 82$ & $2 \cdot 76$ & $2 \cdot 89$ \\
\hline PFR $(1 / \mathrm{min})$ & & & & 425 & 477 & 449 & 440 & 435 & 449 \\
\hline FEF $(1 /$ sec $)$ & & & & $5 \cdot 23$ & $7 \cdot 34$ & 6.67 & $6 \cdot 80$ & $7 \cdot 36$ & $6 \cdot 78$ \\
\hline FMF $(1 / \sec )$ & & & & $2 \cdot 47$ & $3 \cdot 22$ & $2 \cdot 83$ & $2 \cdot 69$ & $2 \cdot 48$ & $\begin{array}{c}2.82 \\
(38.3 \mathrm{yr})\end{array}$ \\
\hline Other underground workers & 3 & 15 & 24 & 27 & 55 & 88 & 62 & 7 & 281 \\
\hline Stature (m) & $1 \cdot 72$ & $1 \cdot 67$ & 1.67 & $1 \cdot 70$ & 1.69 & $1 \cdot 70$ & $1 \cdot 69$ & $1 \cdot 68$ & 1.69 \\
\hline FVC (1) & $4 \cdot 00$ & $3 \cdot 60$ & $3 \cdot 67$ & $3 \cdot 90$ & $3 \cdot 80$ & $3 \cdot 54$ & $3 \cdot 37$ & $3 \cdot 33$ & 3.60 \\
\hline $\mathrm{FEV}_{1}(\mathrm{l})$ & 3.59 & $3 \cdot 10$ & $3 \cdot 17$ & $3 \cdot 33$ & $3 \cdot 15$ & $2 \cdot 86$ & $2 \cdot 72$ & $2 \cdot 72$ & $2 \cdot 98$ \\
\hline $\mathrm{FEV}_{1} / \mathrm{FVC}(\%)$ & $87 \cdot 2$ & $86 \cdot 5$ & $86 \cdot 4$ & $85 \cdot 6$ & $82 \cdot 8$ & $80 \cdot 8$ & $81 \cdot 0$ & $80 \cdot 3$ & $82 \cdot 5$ \\
\hline FMF (1/sec) & $4 \cdot 39$ & 3.91 & $3 \cdot 86$ & $4 \cdot 04$ & 3.41 & $3 \cdot 00$ & $2 \cdot 91$ & $2 \cdot 91$ & $3 \cdot 29$ \\
\hline & & & & & & & & & $(37.5 \mathrm{yr})$ \\
\hline Surface workers & 1 & 7 & 9 & 12 & 19 & 26 & 19 & 3 & 96 \\
\hline Stature (m) & & $1 \cdot 70$ & $1 \cdot 75$ & $1 \cdot 72$ & 1.68 & 1.68 & 1.68 & $1 \cdot 69$ & 1.69 \\
\hline FVC (l) & & 3.68 & $4 \cdot 30$ & $3 \cdot 79$ & $3 \cdot 58$ & 3.43 & $3 \cdot 20$ & 3.01 & $3 \cdot 56$ \\
\hline $\mathrm{FEV}_{1}(1)$ & & $3 \cdot 17$ & $3 \cdot 60$ & $3 \cdot 21$ & $2 \cdot 97$ & $2 \cdot 86$ & $2 \cdot 63$ & $2 \cdot 40$ & $2 \cdot 96$ \\
\hline FEV $_{1} / \mathrm{FVC}(\%)$ & & $86 \cdot 7$ & $83 \cdot 6$ & $84 \cdot 6$ & $82 \cdot 6$ & $83 \cdot 6$ & $81 \cdot 6$ & $80 \cdot 0$ & $83 \cdot 3$ \\
\hline PFR (1/min) & & 507 & 543 & 562 & 459 & 478 & 475 & 468 & 499 \\
\hline FEF $(1 / \mathrm{sec})$ & & $9 \cdot 64$ & $8 \cdot 30$ & $8 \cdot 87$ & $8 \cdot 41$ & $7 \cdot 85$ & $7 \cdot 20$ & $5 \cdot 87$ & $8 \cdot 11$ \\
\hline FMF (I/sec) & & $4 \cdot 03$ & $4 \cdot 31$ & $3 \cdot 59$ & $3 \cdot 20$ & $3 \cdot 28$ & $3 \cdot 77$ & $2 \cdot 07$ & $3 \cdot 33$ \\
\hline
\end{tabular}

Table 3 Comparison of standardised indices of ventilatory capacity between occupational groups of Nigerian miners. All indices have been adjusted to age $=40 \mathrm{yr}$. In addition, FVC, FEV , and PFR have been adjusted to stature $=1.7 \mathrm{~m}$. Mean values and standard errors are shown

\begin{tabular}{|c|c|c|c|c|c|c|c|c|}
\hline & \multirow{2}{*}{$\begin{array}{l}\text { Group } 1 \\
\text { Faceworkers }\end{array}$} & \multirow{2}{*}{$\begin{array}{l}\text { Group } 2 \\
\text { Other } \\
\text { underground }\end{array}$} & \multirow{2}{*}{$\begin{array}{l}\text { Group } 3 \\
\text { Surface }\end{array}$} & \multirow[t]{2}{*}{ Total } & \multicolumn{4}{|c|}{ Significance of differences among groups ( $p$-value) } \\
\hline & & & & & $1 v 2$ & $1 v 3$ & $1 v 2,3$ & $2 v 3$ \\
\hline $\mathrm{FEV}_{1}(1)$ & $\begin{array}{l}2.98 \\
0.029\end{array}$ & $\begin{array}{l}2.95 \\
0.030\end{array}$ & $\begin{array}{l}2.90 \\
0.046\end{array}$ & $\begin{array}{l}2.95 \\
0.019\end{array}$ & NS & NS & NS & NS \\
\hline $\mathrm{FEV}_{1} / \mathrm{FVC}(\%)$ & $\begin{array}{l}80 \cdot 1 \\
0 \cdot 40\end{array}$ & $\begin{array}{c}82 \cdot 0 \\
0.39\end{array}$ & $\begin{array}{l}82.7 \\
0.60\end{array}$ & $\begin{array}{l}81 \cdot 3 \\
0 \cdot 26\end{array}$ & $<0.001$ & $<0.001$ & $<0.001$ & NS \\
\hline FMF (1/sec) & $\begin{array}{l}2.94 \\
0.065\end{array}$ & $\begin{array}{l}3 \cdot 16 \\
0.074\end{array}$ & $\begin{array}{l}3 \cdot 17 \\
0 \cdot 128\end{array}$ & $\begin{array}{l}3.06 \\
0.046\end{array}$ & $<0.05$ & NS & $<0.05$ & NS \\
\hline FEF $(1 / \mathrm{sec})$ & $\begin{array}{l}7 \cdot 12 \\
0 \cdot 18\end{array}$ & $\begin{array}{l}7 \cdot 61 \\
0 \cdot 17\end{array}$ & $\begin{array}{l}8.49 \\
0.40\end{array}$ & $\begin{array}{l}7 \cdot 53 \\
0 \cdot 12\end{array}$ & $<0.05$ & $<0.01$ & $<0.001$ & $<0.05$ \\
\hline PFR (1/min) & $\begin{array}{r}462 \\
4 \cdot 0\end{array}$ & $\begin{array}{r}484 \\
4 \cdot 6\end{array}$ & $\frac{493}{6.5}$ & $\begin{array}{l}476 \\
2 \cdot 8\end{array}$ & $<0.001$ & $<0.001$ & $<0.001$ & NS \\
\hline
\end{tabular}

NS $=$ not significant. 
Table 4 Coefficients of the equation: Variable $=c-d$. Age for each of variables measured in Nigerian miners. Three variables (FVC, FEV , and PFR) have been adjusted to a common stature of $1.7 \mathrm{~m}$, and age-coefficient " $d$ " calculated for the two groups of workers in a multiple regression analysis, keeping a constant intercept. The ratio c/d represents age at which variable would become zero. $p$ value shows significance of difference in " $d$ " between faceworkers and others

\begin{tabular}{|c|c|c|c|c|c|c|}
\hline \multirow[t]{2}{*}{ Variable } & \multirow[b]{2}{*}{$c$} & \multicolumn{2}{|c|}{ Faceworkers $(n=291)$} & \multicolumn{2}{|c|}{ Others $(n=384)$} & \multirow[t]{2}{*}{ p-value } \\
\hline & & $d\left(y r^{-1}\right)$ & $c / d(y r)$ & $d\left(y r^{-1}\right)$ & $c / d(y r)$ & \\
\hline $\begin{array}{l}\text { FVC (1) } \\
\text { FEV } 1 \text { (1) } \\
\text { FEV } / \text { FVC ( } \%) \\
\text { FMF }(1 / \mathrm{sec}) \\
\text { FEF }(1 / \mathrm{sec}) \\
\text { PFR }(1 / \mathrm{min})\end{array}$ & $\begin{array}{c}4 \cdot 457 \\
3 \cdot 967 \\
90 \cdot 51 \\
5 \cdot 181 \\
10 \cdot 31 \\
626 \cdot 1\end{array}$ & $\begin{array}{l}1.885 \times 10^{-2} \\
2.471 \times 10^{-2} \\
2.559 \times 10^{-1} \\
5.555 \times 10^{-2} \\
8.420 \times 10^{-2} \\
4.061\end{array}$ & $\begin{array}{r}236 \\
161 \\
353 \\
93 \\
122 \\
154\end{array}$ & $\begin{array}{l}2.189 \times 10^{-2} \\
2.536 \times 10^{-2} \\
2.058 \times 10^{-1} \\
4.953 \times 10^{-2} \\
6.826 \times 10^{-2} \\
3.423\end{array}$ & $\begin{array}{l}204 \\
156 \\
440 \\
105 \\
151 \\
182\end{array}$ & $\begin{array}{l}<0.005 \\
\text { NS } \\
<0.001 \\
<0.01 \\
<0.005 \\
<0.001\end{array}$ \\
\hline
\end{tabular}

NS $=$ Not significant.

occupation-effect here has been made to affect the slope of the regression on age but not the intercept. The regression equations are therefore exemplified by:

$$
\mathrm{FVC}_{1 \cdot 7}(\mathrm{l})=\mathrm{c}-\mathrm{d}_{\mathbf{i}} \times \text { age }(\mathrm{yr})
$$

where the subscript " $\mathrm{i}$ " indicates that the slope coefficient " $d$ " but not the intercept "c" may vary among occupational groups. Three of the respiratory variables (FVC, FEV 1 , and PFR) were adjusted to a common stature of $1.7 \mathrm{~m}$ as before.

The coefficient " $d$ " for every index was found not to differ significantly between group 3 (surface workers) and group 2 (other underground workers), so for simplicity these two groups have been pooled for comparison with group 1 (the faceworkers) (table 4). The ratio $\mathrm{c} / \mathrm{d}$ denotes the age at which the ventilatory index would decline to zero. Larger values of " $\mathrm{d}$ " represent a steeper decline in ventilatory function with age, and this is seen in faceworkers for FMF, PFR, FEF, and FEV $1 \%$ where the decline with age was $12 \%, 19 \%, 23 \%$, and $24 \%$ steeper respectively. For FVC, however, the decline with age was $14 \%$ less in faceworkers than in the other groups combined.

\section{OTHER INFLUENCES}

The reduction in ventilatory function in faceworkers was explored further by including duration of service as an additional variable in the regression analysis. For example, forced expiratory flow $0.2-1 \cdot 2$ (FEF) declined by a further $0.201 / \mathrm{sec}$ per decade of service independent of age, and $\mathrm{FEV}_{1} \%$ by 0.44 per decade, but these changes were not significant. Nor was there any significant difference between the smokers and the non-smokers within any subgroup, although smokers had a consistently slower decline with age for all variables. Snuff-taking had no influence on the pattern of results.

COMPARISON WITH OTHER NIGERIAN MEN Regression equations providing Nigerian reference
Table 5 Comparison between observed values for three ventilatory indices in Nigerian miners and values predicted from Nigerian reference equations: $F V C(l)=3.513$ stature $(m)-0.0251$ age $(y r)-1.301,7$ $F E V_{1}(l)=4.228$ stature $(m)-0.0232$ age $(y r)-3 \cdot 248,{ }^{7}$ PFR $(\mathrm{l} / \mathrm{min})=327.0$ stature $(\mathrm{m})-1.590$ age $(\mathrm{yr})-14.63^{11}$ using mean stature and age for miners' groups given in table 1

\begin{tabular}{clccccc}
\hline & & $\begin{array}{l}\text { Group 1 } \\
\text { Face- } \\
\text { workers }\end{array}$ & $\begin{array}{l}\text { Group 2 } \\
\text { Other } \\
\text { under- } \\
\text { ground }\end{array}$ & $\begin{array}{l}\text { Group 3 } \\
\text { Surface }\end{array}$ & Total \\
\hline FVC (1) & Observed & 3.63 & 3.60 & 3.56 & 3.60 \\
& Predicted & 3.58 & 3.67 & 3.71 & 3.64 \\
& Ratio & 1.014 & 0.979 & 0.957 & 0.991 \\
FEV 1 (1) & Observed & 2.89 & 2.98 & 2.96 & 2.94 \\
& Predicted & 2.92 & 3.01 & 3.04 & 2.97 \\
& Ratio & 0.990 & 0.987 & 0.975 & 0.988 \\
PFR & Observed & 448.8 & 485.5 & 499.4 & 471.7 \\
(1/min) & Predicted & 472.2 & 477.1 & 481.0 & 474.7 \\
& Ratio & 0.952 & 1.018 & 1.038 & 0.994 \\
\hline
\end{tabular}

values are available only for $\mathrm{FVC}$ and $\mathrm{FEV}_{1}{ }^{7}$ and for PFR. ${ }^{11}$ Predictions for the miners in the present study can be obtained by substituting mean values for the age and stature of the mining groups into these equations (table 5). For all three indices the observed values for the miners as a whole were within $1.5 \%$ of the predicted values. There were, however, systematic differences between the groups. The ratio of observed/predicted was $5.7 \%$ more in faceworkers than in surface workers for FVC, but $8.6 \%$ less for PFR.

\section{Discussion}

This study of Nigerian colliery employees had the limited objective of measuring aspects of ventilatory capacity in asymptomatic men. Ex-miners were not studied, and the survey was confined to a relatively small sample of asymptomatic volunteers currently working in the colliery. It is inevitably biased in favour of healthier men. Any occupational effect on 
ventilatory capacity will therefore have been underestimated.

Only $7 \%$ of the men were smokers, and although the intensity of their smoking history was not recorded, anecdotal evidence suggests that these miners are light smokers. So, despite the reports of rising tobacco consumption in Africa, ${ }^{12}$ cigarette smoking is of minor importance in the present study and did not appear to influence the results materially. This contrasts with the finding of a significant small reduction in $F E V_{1}$ and $F E V_{1} \%$ in smokers among coal miners in both Britain (for instance, ref 2 ) and in America (for instance, ref 13).

Records of forced expirations using the Vitalograph and the peak flow meter provide useful information about the bellows function of the lungs: FVC reflecting variation in effective lung volume, $\mathrm{FEV}_{1} \%$, FEF, and PFR the calibre of large airways; and FMF the calibre of smaller airways. FEV 1 is a hybrid variable depending on both lung size and airway calibre. No great reliance is placed on the measurement of FEF with a Vitalograph, but it is included because it complements the other measures of flow. The adjustment of the measured values of FVC, FEV ${ }_{1}$, and PFR makes little difference to the overall pattern of results because there is no systematic trend in stature and only small age differences among the three groups analysed.

This study, therefore, enables us to answer the question: are the lungs of asymptomatic Nigerian colliery men working at the coalface adversely affected by their occupational environment? The broad answer is that indices reflecting maximum ventilatory airflow were shown to be significantly but modestly lower in faceworkers, while FVC was greater. The differences are seen when the occupational groups are compared for the mean values of age- and stature-adjusted indices (table 3), the trends with age (table 4), and the relation with predicted values (table 5). What could account for them?

Dust in air is not routinely measured in this colliery, and no direct estimate of the dust exposure of these miners is possible. There is, however, likely to be a gradation of exposure between the faceworkers and the surface workers, and the occupational grouping chosen for this analysis was the same as that used by Hankinson et $a l^{5}$ in their study of North American coal miners. It might also be expected that those mine workers with longest service would be most affected, as has been shown for peak flow rates, particularly in non-smokers, ${ }^{5}$ for FEV ${ }_{1} \%{ }^{14}$ and for the prevalence of bronchitis. ${ }^{13}$

Before the differences are firmly ascribed to dust exposure, we must also consider the other features that distinguish the faceworkers from the other groups. They are older, but this has been allowed for.
They smoke less, but smoking has been found to be of little importance anyway. They also probably have a higher customary physical activity. This was not measured, but the energy expenditures of faceworkers and clerks in a Scottish colliery were compared directly by Garry et al, ${ }^{15}$ faceworkers being $30 \%$ more active. The influence of physical training on ventilatory capacity has been reviewed by Cotes. ${ }^{16}$ For example, amateur racing cyclists and highland farmers have been shown to have substantially higher FVC than factory workers and lowland subsistence farmers respectively. ${ }^{17}$ Coal miners use the muscles of their shoulder girdles particularly, which probably increases the strength of the accessory muscles of respiration.

We might have expected to see a modest impairment of FVC in faceworkers. In 267 men randomly selected from a group of 1893 West Virginia miners and ex-miners without pneumoconiosis, FVC was on average $96 \%$ of the predicted normal value and $90 \%$ in the oldest miners with the longest service underground. ${ }^{18}$ On the other hand, Morgan et al ${ }^{19}$ found no deviation in FVC from predicted values in $\mathbf{3 5 0 0}$ miners drawn from many different coal fields across North America. British authors have not reported vital capacity measurements. The finding that Nigerian faceworkers have higher FVC suggests that the effect of muscular training has outweighed any impairment due to dust exposure.

The finding that $F E V_{1}$ is the same in faceworkers and the groups less exposed to dust is surprising in view of the weight of evidence showing that mining is associated with a modest reduction in $\mathrm{FEV}_{1}$ (for instance, 2014 13). Higgins et al, ${ }^{21}$ however, found that the decline in $\mathrm{FEV}_{1}$ was only significant in those miners with over 30 years' service underground. Possibly, in these Nigerian miners the dust-related decline in airway calibre that is commonly manifest as a fall in FEV ${ }_{1}$ is offset by the increase in lung volume due to muscular training and seen here as an increase in FVC. The observation that the ratio of $\mathrm{FEV}_{1}$ to $\mathrm{FVC}\left(\mathrm{FEV}_{1} \%\right)$ is significantly reduced in Nigerian faceworkers suggests that the dust-effect reduces airway calibre more than it does lung volume.

This effect on the larger airways of occupational exposure to dust was clearly shown in the faceworkers' low values for peak flow rate, forced expiratory flow $0 \cdot 2-1 \cdot 2$, and $\mathrm{FEV}_{1} \%$, which were about $9 \%$ less than in the men with minimal exposure (group 3). Forced mid-expiratory flow was also reduced but by a smaller amount. There is no reason to suppose that the muscular training discussed above might have had any direct influence on these flow indices.

If chronic exposure to dust reduces ventilatory 
capacity by narrowing the airways then it is surprising that the impairment of ventilatory function in these miners was not more highly correlated with duration of exposure independent of age. The negative coefficients for age in the regression equations for all indices were materially larger than the coefficients for duration of service, whereas Hankinson et $a l^{5}$ found comparable values when analysing peak flow rates in non-smoking American miners. Possibly the duration of exposure was insufficient to establish the relation decisively in the present study: the median duration of service of the faceworkers was only 10 years, and fewer than $10 \%$ had served underground for more than 20 years. This factor may also explain why the other underground workers (group 2, not faceworkers) had ventilatory indices not significantly different from the surface workers (group 3). Their median service was four years, and only $2 \%$ had worked underground for more than 20 years. Nevertheless, the pattern of results suggests that the same factors that were affecting ventilatory capacity in faceworkers (group 1) were exerting a similar but smaller effect on the men in group 2.

We are greatly indebted to Dr G A Obiora, the chief medical officer and his staff at Colliery Hospital, Enugu, for considerable help in organising this survey and to the Coal Mine Corporation of Nigeria for their permission. Mr P Riley of the Cripps Computer Centre, Nottingham, has given invaluable advice over the analysis. We are grateful for the technical help of Miss Ronkey Akindoju and Miss Jane Baker. JMP is grateful for leave of absence from the University of Nottingham, and for travel facilities granted by the Medical School, University of Calabar, Nigeria.

No reprints will be available from the authors.

\section{References}

${ }^{1}$ Higgins ITT, Oldham PD. Ventilatory capacity in miners; a five-year follow-up study. Br J Ind Med 1962;19:65-76.

2 Ashford JR, Brown S, Morgan DC, Rae S. The pulmonary ventilatory function of coal miners in the UK. Am Rev Respir Dis 1968;97:810-26.

${ }^{3}$ Muir DCF. Pulmonary function in miners working in
British collieries: epidemiological investigations by the National Coal Board. Bulletin de Physiopathologie Respiratoire 1975;11:403-14.

4 Minette A. Epidemiological contribution to the etiology of chronic bronchitis VI. Summary of the results of observations on various miners. Revue de l'Institut d'Hygiene des Mines 1976;31:153-69, 191-203.

${ }^{5}$ Hankinson JL, Reger RB, Fairman RP, Lapp NL, Morgan WKC. Factors influencing expiratory flow rates in coal miners. In: Walton WH, ed. Inhaled Particles IV. New York: Pergamon, 1977:737-55.

- Goldstein B, Webster I. Coal workers' pneumoconiosis in South Africa. Ann NY Acad Sci 1972;200:306-15.

7 Patrick JM, Femi-Pearse D. Reference values for FEV ${ }_{1}$ and FVC in Nigerian men and women: a graphical summary. Niger Med J 1976;6:380-5.

${ }^{8}$ Jain BL, Gupta D. Effect of age, height and weight on lung function in healthy adult Nigerians. Niger Med $J$ (in press).

- Bouhuys A. Pulmonary function measurements in epidemiological studies. Bulletin de Physiopathologie Respiratoire 1970;6:561-78.

${ }^{10}$ Cole TJ. Linear and proportional regression models in the prediction of ventilatory function. Journal of the Royal Statistical Society A 1975;138:297-338.

${ }^{11}$ Femi-Pearse D. Ventilatory function including anthropometric correlations in Nigerians. University of Aberdeen, 1969. (MD Thesis.)

12 Taha A, Ball K. Smoking and Africa: the coming epidemic. Br Med J 1980;280:991-3.

${ }^{13}$ Kibelstis JA, Morgan EJ, Reger R, Lapp NL, Seaton A, Morgan WKC. Prevalence of bronchitis and airway obstruction in American bituminous coal miners. Am Rev Respir Dis 1973;108:886-93.

${ }^{14}$ Lowe CR, Khosla T. Chronic bronchitis in ex-coal miners working in the steel industry. Br J Ind Med 1972;29: 45-9.

15 Garry RC, Passmore R, Warnock GM, Durnin JGVA. Studies on expenditure of energy and consumption of food by miners and clerks, Fife, Scotland, 1952. London: Medical Research Council, 1955. (Special Report Series No 289.)

${ }^{16}$ Cotes JE. Lung function. 4th ed. Oxford: Blackwell, 1979.

17 Cotes JE, Anderson HR, Patrick JM. Lung function in response to exercise in New Guineans: role of genetic and environmental factors. Philos Trans $R$ Soc Lond (Biol) $1974 ; 268: 349-61$.

${ }^{18}$ Hyatt RE, Kistin AD, Mahan TK. Respiratory disease in Southern West Virginia coal miners. Am Rev Respir Dis 1964;89:387-401.

19 Morgan WKC, Handelsman L, Kibelstis J, Lapp L, Reger R. Ventilatory capacity and lung volumes of US coal miners. Arch Environ Health 1974;28:182-9.

${ }^{20}$ Higgins ITT, Cochrane AL, Gilson JC, Wood $\mathrm{CH}$. Population studies of chronic respiratory disease: a comparison of miners, foundry workers, and others in Staveley, Derbyshire. Br J Ind Med 1959;16:255-68.

${ }^{21}$ Higgins ITT, Higgins MW, Lockshin MD, Canale N. Coronary disease in mining communities in Marion County, West Virginia. J Chronic Dis 1969;22:165-79. 